\title{
Environmental life cycle assessment of supercapacitor electrode production using algae derived biochar aerogel
}

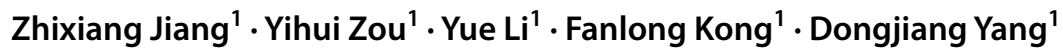

Received: 3 February 2021 / Accepted: 2 September 2021 / Published online: 4 October 2021

(c) The Author(s) 2021

\begin{abstract}
Porous carbon aerogel material has gained an increasing attraction for developing supercapacitor electrodes due to its costeffective synthesis process and relatively high electrochemical performance. However, the environmental performances of supercapacitor electrodes produced from different carbon aerogel materials are never comparatively studied, hindering our knowledge of supercapacitor electrode production in a sustainable pattern. In this study, nitrogen-doped biochar aerogel-based electrode (BA-electrode) produced from Entermorpha prolifera was simulated to investigate the environmental performance by using life cycle assessment method. For comparison, the assessment of graphene oxide aerogel-based electrode (GOAelectrode) was also carried out. It can be observed that the life cycle global warming potential for the BA-electrode was lower than that of GOA-electrode with a reduction of 53.1-68.1\%. In comparison with GOA-electrode, the BA-electrodes endowed smaller impacts on environment in majority of impact categories. Moreover, in comparison with GOA-electrode, the environmental damages of BA-electrode were greatly decreased by $35.8-56.4 \%$ (human health), 44.9-62.6\% (ecosystems), and $87.0-91.2 \%$ (resources), respectively. The production stages of GOA and graphene oxide and stages of nitrogen-doped biochar aerogel production and Entermorpha prolifera drying were identified as the hotspots of environmental impact/damage for the GOA-electrode and BA-electrode, respectively. Overall, this finding highlights the efficient utilization of algae feedstock to construct a green and sustainable technical route of supercapacitor electrode production.
\end{abstract}

Keywords Nitrogen-doped biochar aerogel $\cdot$ Graphene oxide aerogel $\cdot$ Supercapacitor electrode $\cdot$ Life cycle assessment . Algae

\section{Introduction}

With a fast-growing market for portable electronic devices and the development of hybrid electric vehicles, it is necessary to develop high-power energy-storage devices. Supercapacitors, also known as electrochemical capacitors or ultracapacitors, are considered as one of the potential candidates among energy-storage devices due to their rapid charge-discharge performance and long cycling life (Miller and Simon 2008; Zhang and Zhao 2009). Carbon-based electrodes have attracted wide concern owing to their high conductivity, large specific surface area and bipolar operational flexibility (Pandolfo and Hollenkamp 2006). For example, Wang et al. (2015) have reported three-dimensional carbon nanotubes as

Dongjiang Yang

d.yang@qdu.edu.cn

1 College of Environmental Science and Engineering, Qingdao University, Qingdao 266071, China electrode materials for supercapacitor, which exhibit specific capacitance of $229 \mathrm{~F} \mathrm{~g}^{-1}$ at current density of $1 \mathrm{~A} \mathrm{~g}^{-1}$. More recently, the graphene oxide aerogel (GOA)-based electrode (GOA-electrode) has shown to have a better electrochemical performance (energy and power density and long-term durability) than that of graphene oxide (Garcia-Bordeje et al. 2018; Guo et al. 2020a, b; Ng et al. 2015). However, the further development of these carbon-based electrode materials using inorganic feedstocks (e.g., the graphite) as precursors has negative influences on non-renewable resource depletion and greenhouse gas emission (Sun et al. 2011; Wang et al. 2017).

Recently, biochar has attracted extensive interest for both fundamental research and practical applications in various electrochemical devices (Lu et al. 2020). Biochars derived from various types of marine algae have been ideally suited as electrode materials for supercapacitor (Cui et al. 2016), because of their unique advantages of porous structure with multilayer, excellent mechanical flexibility and integrity, and 
tunable multifunctionality. For example, Raymundo-Piñero et al. (2006) prepared active carbon materials by direct carbonization using algae as raw materials and exhibited a specific capacity of $198 \mathrm{~F} \mathrm{~g}^{-1}$. More recently, our group investigated the electrochemical performance of marine algae derived biochar aerogel-based electrodes (BA-electrodes) for battery and supercapacitor (Cui et al. 2016; Li et al. 2018). These studies confirmed that these BA-electrodes exhibit comparative or even better electrochemical performance when compared to those produced from other inorganic feedstocks. Particularly, the nitrogen-doped biochar aerogel material synthesized from Entermorpha prolifera (EP) was an ideal candidate for supercapacitor electrode production due to its porous structure with multilayer and high specific surface area. Moreover, the EP is one of the common algae pollutions in the Yellow Sea (Gao et al. 2014). It has imposed serious and negative impacts on the marine ecology, fishery production, and coastal landscape, as well as a big challenge for solid waste management (Cui et al. 2016). Therefore, it could potentially establish a green and sustainable pathway for carbon-based electrode production using marine algae, especially for the EP pollution. However, most of the previous studies focused on the micro/nanostructures (Xu et al. 2019), strategies for tailoring the structures and morphologies (Lv et al. 2019; Zou et al. 2020), as well as their impact on electrochemical performance (Guo et al. 2020a). The studies on investigation of the environment performance of algae feedstock-derived carbon-based electrode and its comparison with other traditional carbonbased electrodes are missing. This seriously limits the deep understanding of scientific and comprehensive evaluation on supercapacitor development using carbon-based electrodes produced from different inorganic and organic raw feedstocks.

The life cycle assessment (LCA), initially developed by the Society of Environmental Toxicology and Chemistry (SETAC) and later standardized by the ISO (ISO-14040 2006; ISO-14044, 2006), has been regarded as one of most useful methods to systematically explore the environmental performance of a product or a technology (Hellweg et al. 2014; Guinée et al. 2011). In previous studies, this method has been widely employed in various fields, such as the bioenergy production and application (Dasan et al. 2019; Ertem et al. 2017), biochar production and application (Muñoz et al. 2017), agricultural production practices (Jiang et al. 2021), and others. Aiming at the electrode material field, the LCA method was also employed to explore environmental effects or environment improvement potentials of emerging electrode materials (e.g., metal oxides/hydroxides) used in lithium-ion or sodium-ion batteries (Glogic et al. 2019; Malara et al. 2020; Padashbarmchi et al. 2015; $\mathrm{Wu}$ et al. 2019). These studies confirmed that, compared to the traditional electrode materials, the advanced electrode materials demonstrated a lower environmental implication, but that highly depended on metal oxide species and synthetic method. However, little information has been published to ascertain the environmental performances of different carbon aerogel-based electrodes used in a supercapacitor which can be widely applied in portable and miniaturized devices (Poonam et al. 2019). Herein, to fill the knowledge gaps mentioned above, the LCA method was used to (1) quantitatively assess and compare the environmental performances of BA-electrode and commonly used GOA-electrode and (2) identify hotspot life cycle stages for each assessed environmental indicator. Notably, supercapacitor is a symmetrical capacitor, in which the cathode and anode are the same. This means the carbon aerogel materials can be used for both cathode and anode electrode productions. Overall, this study reports the environmental performance of the advanced supercapacitor electrode production for the first time using carbon aerogel-based materials from graphite and EP feedstocks.

\section{Materials and methods}

\subsection{Definition of LCA: goal, system boundary, and functional unit}

In this study, the goal was to comparatively assess the environmental performances of BA-electrode and GOA-electrode. Moreover, hotspot life cycle stages for each assessed environmental impact/damage category and each technology, and the environmental improvement potentials were also identified. As shown in Fig. 1, system boundaries of the two technologies were defined. For the BA-electrode technology, the impacts of EP collection on the sea, biochar aerogel production, and the transportation between these two stages were considered. Regarding the commercial GOA-electrode, the productions of graphite, graphene oxide, and GOA and the transportations linking stages were included. Notably, same technical processes and materials/ energy input for supercapacitor production were assumed in the present LCA, and the only difference between these two technologies was the input amount of carbon aerogelbased electrode needed for per-unit supercapacitor production. Therefore, the supercapacitor fabrication process was not included in the present LCA. The detailed information related to the technical processes of productions of graphene oxide, GOA, and EP derived biochar aerogel (EP-BA) can be seen in Fig. 2. Furthermore, as the usual way to deal with infrastructure and production equipment required to maintain the production process in former LCA studies, these two aspects were not included in the system boundaries due to their negligible environmental impacts on the total LCA results (Jiang et al. 2021; Cossutta et al. 2020). The 
Fig. 1 Life cycle system boundaries for a $5 \mathrm{~F}$ supercapacitor unit with two carbon aerogelbased electrode scenarios. GOA and GOA-electrode represent the graphene oxide aerogel and GOA-based electrode. EP, EP-BA, and BA-electrode represent the Entermorpha prolifera, nitrogen-doped biochar aerogel produced from EP, and EPBA-based electrode. The blue figures within brackets indicate the feedstock/mid-product for each life cycle stage.

\section{System boundaries}

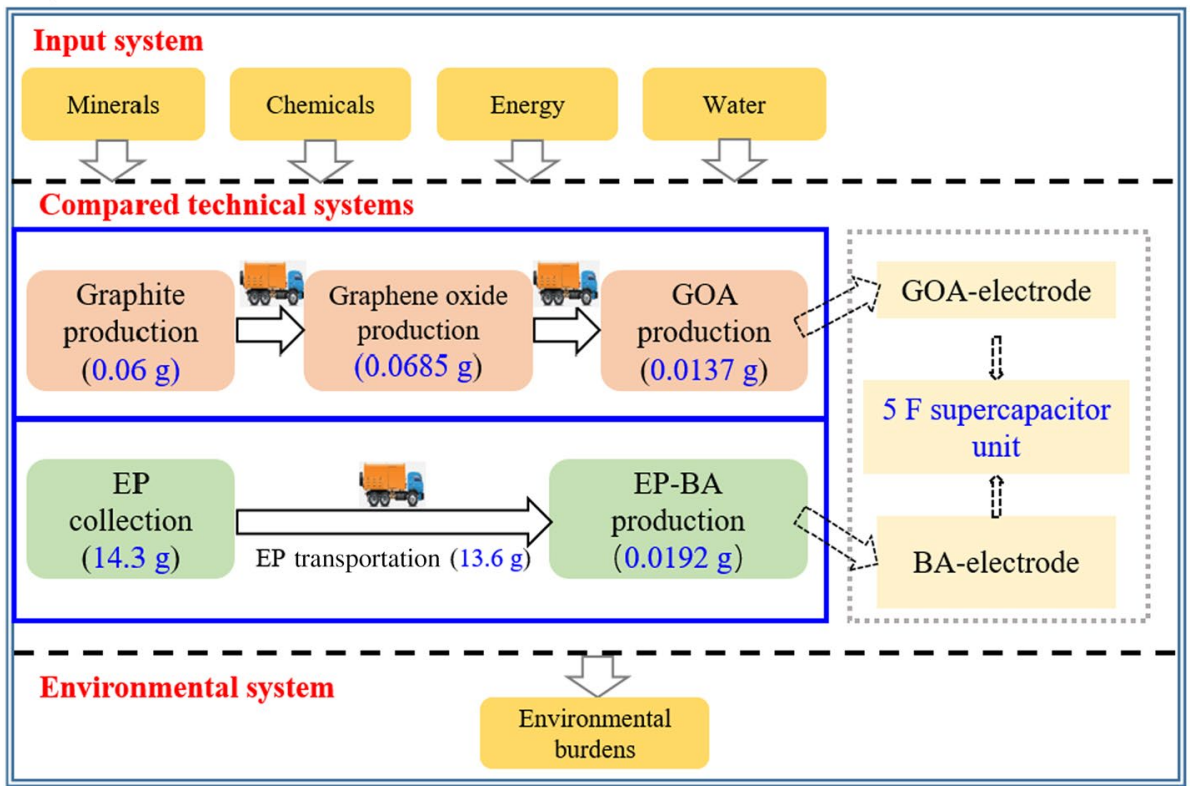

functional unit of LCA was defined as a supercapacitor with capacitance of $5 \mathrm{~F}$.

\subsection{Life cycle impact assessment}

In the present LCA study, the SimaPro software (version 8.5.0; PRé Consultants 2017) was used, and the default hierarchist versions of midpoint and endpoint methods were employed to calculate the environmental impact and damage results, respectively. In total, eighteen impact categories and three damage categories were explored by the midpoint and endpoint methods, respectively, and the list and abbreviations (when applicable) for the assessed environmental indicators are presented in Table 1.

\subsection{Life cycle inventory analysis}

\subsubsection{EP-BA production}

Three primary life cycle stages are comprised for the BAelectrode technology, including on-sea collection of EP feedstock, EP feedstock transportation from sea-side to EP-BA production plant, and EP-BA production (Fig. 1). Based on the field survey, the diesel consumption for collecting $1 \mathrm{t}$ fresh EP (95\% moisture content) from the offshore area to the land using a trawler was estimated to be $0.62 \mathrm{~L}$, on average, equaling to $18 \mathrm{MJ}$. The inventory analysis for the EP feedstock transportation from sea-side to EP-BA production plant can be seen in "2.3.3 Materials transportations" section. The EP-BA production and its electrochemical performance were derived from our previously published study of Cui et al. (2016). As shown in Fig. 2a, three distinct steps of fresh EP drying, EP aerogel preparation, and EP-BA synthesis were included. For the fresh EP drying, the method of centrifugal dewatering combined with pump drying was adopted to decrease the moisture content of EP from the $95 \%$ to $5 \%$ due to its advantages related to desalt and high energy use efficiency (Wang et al. 2009). Moreover, according to the study of Wang et al. (2009), the combination of centrifugal dewatering (20 min) with heat pump drying (48 min) demonstrated the lowest energy consumption and economic cost when compared with other methods of centrifugal dewatering combined with different drying modes. Therefore, the energy consumption for acquiring $1 \mathrm{~kg}$ dry EP (moisture content, 5\%) was assumed to be 4.00 $\mathrm{kWh}$, equaling to 14.4 MJ (Wang et al. 2009). During the step of EP aerogel preparation, the dried EP was successively subjected to the treatments of ultrasonic dispersion, decoloration, and impurities removal by using an acidified $\mathrm{NaClO}_{2}$, and freeze-drying. Then almost all of sugar, starch, and pectin in original EP feedstock were removed (Cui et al. 2016). Regarding the last step of EP-BA synthesis, the prepared EP aerogel was firstly carbonized at $700{ }^{\circ} \mathrm{C}$ for $1 \mathrm{~h}$ under the nitrogen atmosphere, and subsequently activated by using potassium hydroxide and pyrolyzed at $900{ }^{\circ} \mathrm{C}$ for $2 \mathrm{~h}$ (Cui et al. 2016). For the basic scenario of EP-BA, a medium specific capacitance $\left(261 \mathrm{~F} \mathrm{~g}^{-1}\right.$ ) was used (Cui et al. 2016), where the mass quantity of EP-BA needed for a supercapacitor with capacitance of $5 \mathrm{~F}$ was calculated to be $0.0192 \mathrm{~g}$. Notably, the carbon sequestrated in the EP-BA should be taken into consideration, because this portion of carbon is derived from the atmospheric $\mathrm{CO}_{2}$ assimilated by the photosynthesis of EP. According to our measured data, the carbon content of EP-BA was $67.0 \%$, and, therefore, the 
Fig. 2. Technical processes for the productions of nitrogendoped biochar aerogel from Entermorpha prolifera (EP-BA)

(a), reduced graphene oxide

(b), and graphene oxide aerogel (GOA) (c) (a)

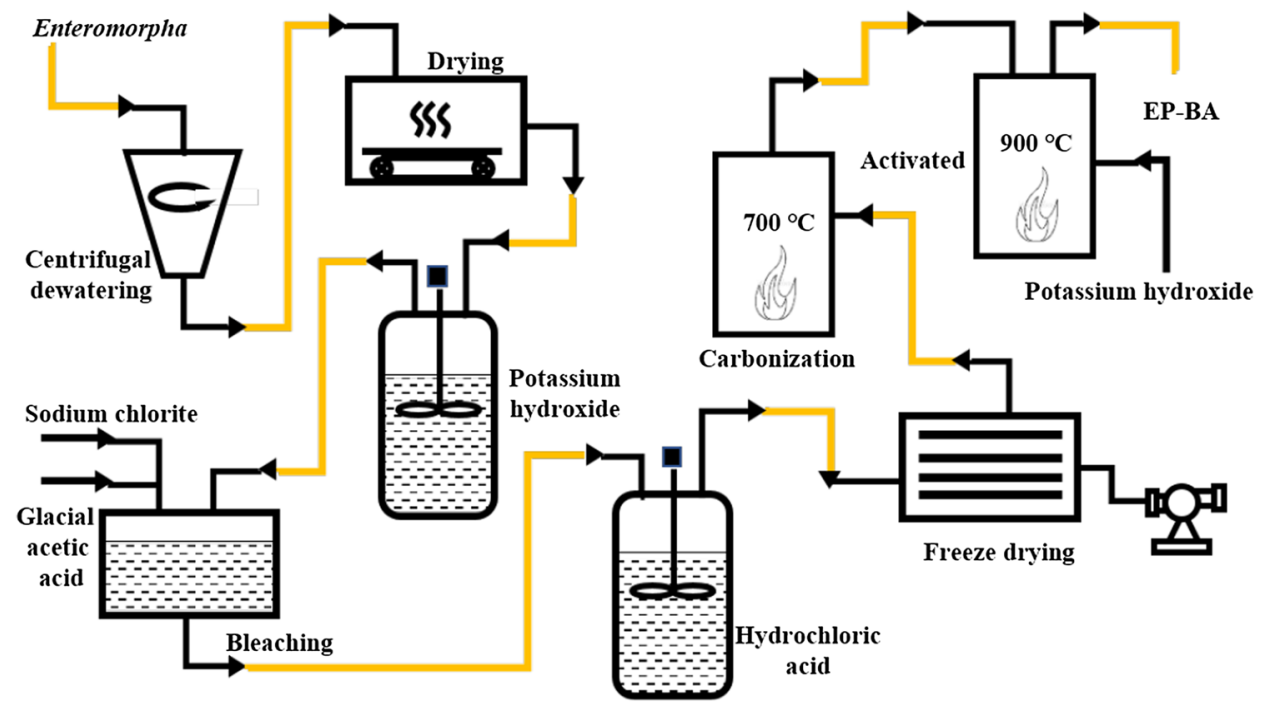

(b)

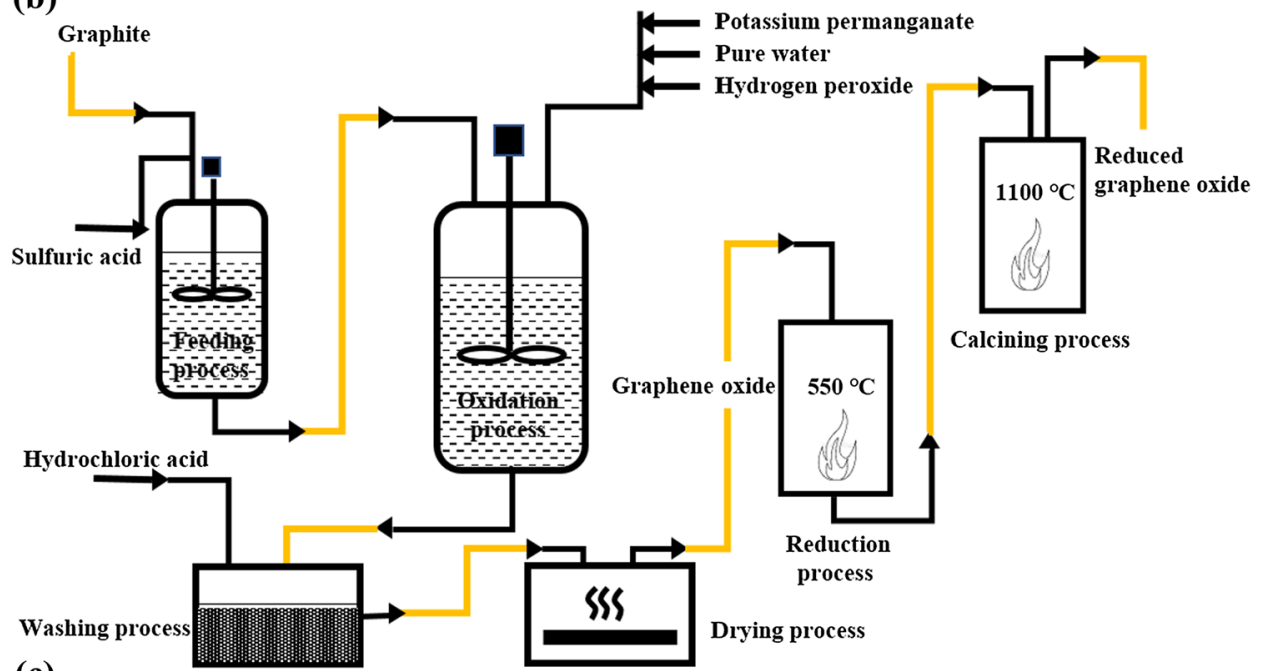

(c)

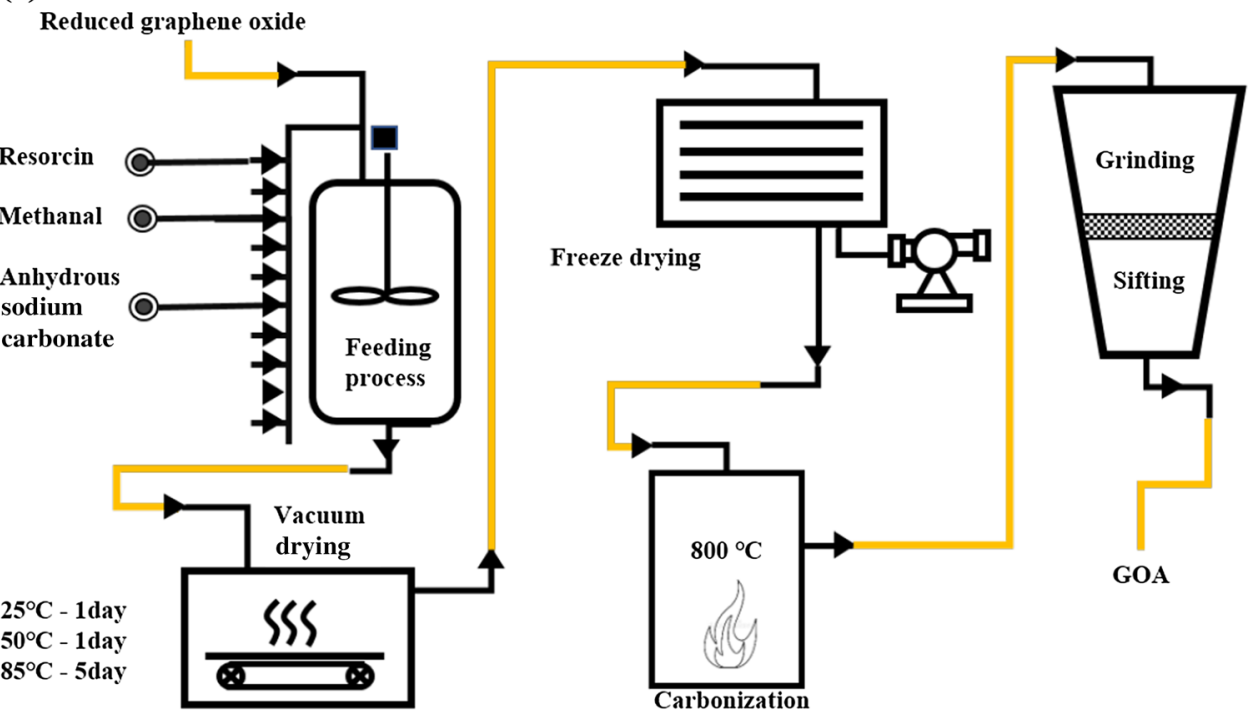


Table 1 Lists and abbreviations (when applicable) of impact and damage categories at midpoint and endpoint levels, respectively, according to ReCiPe 2016 methodology

\begin{tabular}{|c|c|c|c|c|c|}
\hline Impact category & Unit & Abbreviation & Impact category & Unit & Abbreviation \\
\hline Global warming potential & $\mathrm{kg} \mathrm{CO}_{2 \text {-eq }}$ & GWP & Terrestrial ecotoxicity & kg 1,4-DCB & T-ET \\
\hline Stratospheric ozone depletion & $\mathrm{kg} \mathrm{CFC} 11_{-\mathrm{eq}}$ & SOD & Freshwater ecotoxicity & $\mathrm{kg} 1,4-\mathrm{DCB}$ & F-ET \\
\hline Ionizing radiation & $\mathrm{kBq}$ Co- $60_{-\mathrm{eq}}$ & IR & Marine ecotoxicity & kg 1,4-DCB & M-ET \\
\hline Ozone formation (human health) & $\mathrm{kg} \mathrm{NO} \mathrm{x}_{\mathrm{x} \text { eq }}$ & $\mathrm{OF}-\mathrm{HH}$ & Human carcinogenic toxicity & kg 1,4-DCB & HCT \\
\hline Fine particulate matter formation & $\mathrm{kg} \mathrm{PM}_{2.5 \text {-eq }}$ & FPMF & Human non-carcinogenic toxicity & kg 1,4-DCB & HNCT \\
\hline Ozone formation (terrestrial ecosystems) & $\mathrm{kg} \mathrm{NO}_{\mathrm{x} \text {-eq }}$ & OF-TE & Land use & $\mathrm{m}^{2} \mathrm{a}$ crop $_{\text {-eq }}$ & LU \\
\hline Terrestrial acidification & $\mathrm{kg} \mathrm{SO}_{2-\mathrm{eq}}$ & TA & Mineral resource scarcity & $\mathrm{kg} \mathrm{Cu}_{-\mathrm{eq}}$ & MRS \\
\hline Freshwater eutrophication & $\mathrm{kg} \mathrm{P}_{-}{ }_{\mathrm{eq}}$ & F-EU & Fossil resource scarcity & $\mathrm{kg}$ oil $_{-\mathrm{eq}}$ & FRS \\
\hline Marine eutrophication & $\mathrm{kg} \mathrm{N}_{\text {-eq }}$ & M-EU & Fresh water consumption & $\mathrm{m}^{3}$ & WC \\
\hline \multicolumn{6}{|l|}{ Damage category } \\
\hline Human health & DALY & - & Resources & USD2013 & - \\
\hline Ecosystems & species.yr ${ }^{-1}$ & - & & & \\
\hline
\end{tabular}

carbon sequestration of $1 \mathrm{~kg}$ EP-BA was $2.52 \mathrm{~kg} \mathrm{CO}_{2 \text {-eq }}$ (the transformation coefficient for carbon to $\mathrm{CO}_{2}$ is 3.67), equaling to $0.05 \times 10^{-3} \mathrm{~kg} \mathrm{CO}_{2 \text {-eq }}$ (functional unit) ${ }^{-1}$ for the basic BA-electrode scenario.

\subsubsection{GOA production}

The graphite production process was taken directly from the database of the SimaPro software (PRé Consultants 2017). For the reduced graphene oxide production, an inexpensive and scalable production technology was chosen, which has been already well-defined in previous study (Cossutta et al. 2020). Briefly, two successive steps were included to produce the graphene oxide using the graphite as a precursor, including chemical oxidation of graphite powder and thermal-chemical conversion (Fig. 2b). For the former, the graphite powder is firstly added into sulfuric acid solution, followed by the oxidation process with hydrogen peroxide and potassium permanganate, and then the oxidized product is washed with hydrochloric acid and dried in an oven. For the later, the processes of reduction at $550{ }^{\circ} \mathrm{C}$ and calcining in $1100{ }^{\circ} \mathrm{C}$ are employed to obtain the final graphene oxide production. The inventory data for the graphene oxide production was directly extracted from the study of Cossutta et al. (2020). Regarding the GOA, the modified production method originating from the prototype published by Guo et al. (2020b) was selected due to its simplicity and economy. As shown in Fig. 2c, five successive steps were included: (1) feeding process, in which the reduced graphene oxide was completely dissolved in the mixed solutions of resorcin, methanal, and anhydrous sodium carbonate assisted by the ultrasonic agitation; (2) vacuum drying; (3) freeze drying; (4) carbonization at $800{ }^{\circ} \mathrm{C}$ for $1 \mathrm{~h}$; and (5) finally grinding and sifting. According to the results published in Guo et al. (2020b), the highest specific capacitance of GOA could reach up to $364 \mathrm{~F} \mathrm{~g}^{-1}$. So the mass quantity of GOA needed for a supercapacitor with capacitance of $5 \mathrm{~F}$ was calculated to be $0.0137 \mathrm{~g}$.

\subsubsection{Materials transportations}

As illustrated in Fig. 1, graphite, graphene oxide, GOA, EP, and EP-BA from the raw material factories (or raw material collection site) to the product factories were involved in the materials transportation process. As reported by Zhu et al. (2018), the average product transportation distances within surrounding cities and across the country were assumed to be 560 and $850 \mathrm{~km}$. In the present LCA, we assumed that all the materials/products were sold in the adjacent area. On the other hand, the transportation process has been reported to have only a tiny contribution to the overall LCA result in other relevant systems of bioenergy or biochar technology (Jiang et al. 2021; Roberts et al. 2010), which was also confirmed in the present study as shown in the Sect. "Results and discussion". Therefore, the average transportation distance was roughly assumed to be $500 \mathrm{~km}$. The average transportation distance for the fresh EP feedstock was assumed to be $55 \mathrm{~km}$, which was determined based on field survey of the EP transportation distances from collection sites to treatment sites, e.g., 43.8, 57, and $63 \mathrm{~km}$. In addition, a 5\% loss rate was assumed for the EP during the processes of collection and transportation, respectively (Jiang et al. 2021), while no loss was assumed for the graphene oxide, GOA, and EP-BA during transportations owing to their good packaging.

The completed inventory analyses of each life cycle stage for the GOA-electrode and BA-electrode are presented in Tables 2 and 3 . 
Table 2 Inventory analysis of each life cycle stage for the graphene oxide aerogel-based electrode (GOA-electrode)

\begin{tabular}{|c|c|c|c|c|}
\hline Input item & Quantity & Note & Output item & Quantity \\
\hline \multicolumn{5}{|l|}{ Graphite production } \\
\hline Data from the SimaPro directly & & & Graphite/kg & 1.00 \\
\hline \multicolumn{5}{|l|}{ Graphite transportation } \\
\hline Graphite/tkm & $5.00 \mathrm{E}-01$ & Transportation distance: $500 \mathrm{~km}$ & Graphite/kg & 1.00 \\
\hline \multicolumn{5}{|l|}{ Reduced graphene oxide production $^{\mathrm{a}}$} \\
\hline Graphite/kg & $8.90 \mathrm{E}-01$ & & Graphene oxide $/ \mathrm{kg}$ & 1.00 \\
\hline Ammonia/kg & $9.00 \mathrm{E}-02$ & & & \\
\hline Electricity/MJ & $8.00 \mathrm{E}+00$ & & & \\
\hline Ethanol/kg & $1.00 \mathrm{E}+01$ & & & \\
\hline Hydrazine/kg & $1.38 \mathrm{E}+00$ & & & \\
\hline Hydrogen peroxide $(100 \%) / \mathrm{kg}$ & $1.55 \mathrm{E}+00$ & & & \\
\hline Potassium permanganate/kg & $2.68 \mathrm{E}+00$ & & & \\
\hline Sodium nitrate $/ \mathrm{kg}$ & $4.50 \mathrm{E}-01$ & & & \\
\hline Sulphuric acid aq. $(96 \%) / \mathrm{kg}$ & $3.78 \mathrm{E}+00$ & & & \\
\hline Water (deionised)/kg & $2.80 \mathrm{E}+02$ & & & \\
\hline Calcium hydroxide (for neutralisation) $/ \mathrm{kg}$ & $2.85 \mathrm{E}+00$ & & & \\
\hline \multicolumn{5}{|l|}{ Graphene oxide transportation } \\
\hline Graphene oxide/tkm & $5.00 \mathrm{E}-04$ & Transportation distance: $500 \mathrm{~km}$ & Graphene oxide $/ \mathrm{kg}$ & 1.00 \\
\hline \multicolumn{5}{|l|}{ Graphene oxide aerosol (GOA) production ${ }^{\mathrm{b}}$} \\
\hline Graphene oxide/kg & $5.00 \mathrm{E}+00$ & & $\mathrm{GOA} / \mathrm{kg}$ & 1.00 \\
\hline Resorcinol/kg & $3.20 \mathrm{E}+02$ & & $\mathrm{CO}_{2}$ emission $/ \mathrm{kg}$ & 6.61 \\
\hline Formaldehyde kg & $1.75 \mathrm{E}+02$ & & & \\
\hline Anhydrous sodium carbonate $/ \mathrm{kg}$ & $6.00 \mathrm{E}-01$ & & & \\
\hline Electricity/MJ & $2.90 \mathrm{E}+00$ & Freeze drying & & \\
\hline Electricity/MJ & $1.15 \mathrm{E}+01$ & Drying & & \\
\hline Electricity/MJ & $5.80 \mathrm{E}-01$ & Carbonization $^{\mathrm{c}}$ & & \\
\hline \multicolumn{5}{|l|}{ GOA transportation } \\
\hline $\mathrm{GOA} / \mathrm{tkm}$ & $5.00 \mathrm{E}-04$ & Transportation distance: $500 \mathrm{~km}$ & GOA & 1.00 \\
\hline
\end{tabular}

${ }^{\mathrm{a}}$ Cossutta et al. (2020)

${ }^{\mathrm{b}}$ The mass input for $1 \mathrm{~kg}$ GOA production was compiled from Guo et al. (2020b), and the electricity consumptions for freeze drying and drying were calculated based on the experimental data

${ }^{c}$ Roberts et al. (2010)

\subsection{Uncertainty analysis and data processing}

In order to explore the absolute uncertainties of the assessed LCA results, the Monte Carlo simulations were performed in the SimaPro software (PRé Consultants 2017), and the mean and standard deviation of LCA results were presented under an assumption of a $95 \%$ confidence interval. Furthermore, two additional BA-electrode scenarios of the BA-electrode with low or high specific capacitances (190 and $280 \mathrm{~F} \mathrm{~g}^{-1}$ ), named as the BA-electrode (Low) and BA-electrode (High), were considered to explore the effect of electrochemical performance on the overall LCA results of BA-electrode technology. The LCA results were output by the SimPro software, and the data processing and figures plotting were performed using the Microsoft Excel 2016 and Origin 2017.

\section{Results and discussion}

\subsection{Life cycle results of GWP}

The life cycle results of GWP for the BA-electrodes and GOA-electrode are presented in Fig. 3. Notably, although the specific capacitance for the EP-BA $\left(190-280 \mathrm{~F} \mathrm{~g}^{-1}\right)$ was greatly lower than that of the GOA $\left(364 \mathrm{~F} \mathrm{~g}^{-1}\right)$, the assessed life cycle GWPs for the former $\left[6.25 \times 10^{-3}-9.20 \times 10^{-3} \mathrm{~kg}\right.$ $\mathrm{CO}_{2 \text {-eq }}$ (functional unit) ${ }^{-1}$ ] were about 2 or 3 times lower than that of the latter. This indicates that there is a big potential of GWP mitigation when using the EP-BA to replace the GOA as the electrode material for supercapacitor production. As the production processes outlined in Fig. 1, only one process was included for the EP-BA synthesis from the raw EP material to electrode material, while three processes 
Table 3 Inventory analysis of each life cycle stage for the nitrogen-doped biochar aerogelbased electrode (BA-electrode) produced from Enteromorpha Prolifera

\begin{tabular}{|c|c|c|c|c|}
\hline Input item & Quantity & Note & Output item & Quantity \\
\hline \multicolumn{5}{|c|}{ Enteromorpha Prolifera $(\mathrm{EP})$ collection $^{\mathrm{a}}$} \\
\hline Diesel/MJ & $1.80 \mathrm{E}-02$ & $95 \% \mathrm{MC}^{\mathrm{b}}$ and $5 \%$ loss rate & Fresh EP/kg & 1.00 \\
\hline \multicolumn{5}{|l|}{ Fresh EP transportation } \\
\hline Fresh EP/tkm & $5.50 \mathrm{E}+01$ & $\begin{array}{l}95 \% \mathrm{MC} \text { and } 5 \% \text { loss rate; } \\
\text { Transportation distance: } 55 \mathrm{~km}^{\mathrm{c}}\end{array}$ & Fresh EP/kg & 1.00 \\
\hline \multicolumn{5}{|c|}{ Nitrogen-doped biochar aerogel (EP-BA) production ${ }^{\mathrm{d}}$} \\
\hline Fresh EP/kg & $6.72 \mathrm{E}+02$ & $95 \% \mathrm{MC}$ & $\mathrm{EP}-\mathrm{BA} / \mathrm{kg}$ & 1.00 \\
\hline Electricity/MJ & $4.75 \mathrm{E}+02$ & Fresh EP drying ${ }^{\mathrm{e}}$ & & \\
\hline Potassium hydroxide/kg & $7.00 \mathrm{E}+01$ & & $\begin{array}{c}\mathrm{C} \text { sequestra- } \\
\text { tion } / \mathrm{kg} \\
\mathrm{CO}_{2-\mathrm{eq}}\end{array}$ & 2.52 \\
\hline Hydrochloric acid $/ \mathrm{kg}$ & $1.20 \mathrm{E}+01$ & & & \\
\hline $\mathrm{NaClO}_{2} / \mathrm{kg}$ & $1.33 \mathrm{E}+01$ & & & \\
\hline Glacial acetic acid $/ \mathrm{kg}$ & $1.00 \mathrm{E}+01$ & & & \\
\hline Electricity/MJ & $9.00 \mathrm{E}-01$ & Freeze drying & & \\
\hline Electricity/MJ & $3.50 \mathrm{E}+00$ & Drying & & \\
\hline Electricity/MJ & $5.80 \mathrm{E}-01$ & Carbonization ${ }^{\mathrm{f}}$ & & \\
\hline \multicolumn{5}{|l|}{ EP-BA transportation } \\
\hline EP-BA/tkm & $5.00 \mathrm{E}-01$ & Transportation distance: $500 \mathrm{~km}$ & EP-BA/kg & 1.00 \\
\hline
\end{tabular}

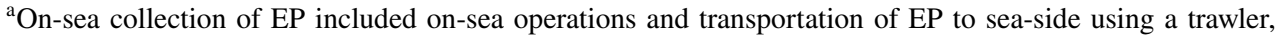
and the energy (diesel) consumption data was acquired based on a field survey

${ }^{b} M C$ moisture content

${ }^{c}$ Determined based on the survey of practical transportation distances from the EP collection sits to the treatment sites

${ }^{\mathrm{d}}$ The mass input for $1 \mathrm{~kg}$ EP-BA (nitrogen-doped biochar aerogel from EP) production was compiled from Cui et al. (2016), and the electricity consumptions for freeze drying and drying were calculated based on the experimental data

${ }^{\mathrm{e}}$ Wang et al. (2009)

${ }^{\mathrm{f}}$ Roberts et al. (2010)

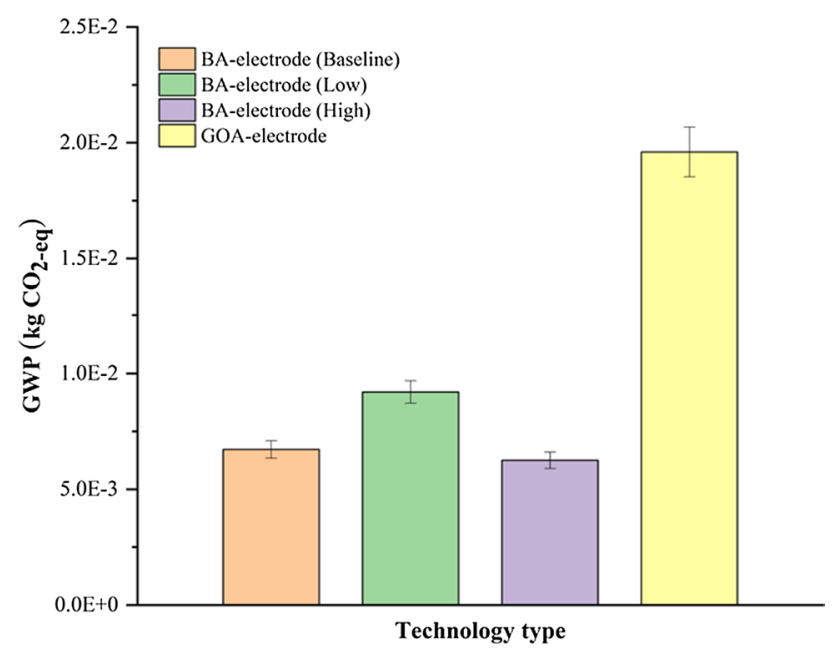

Fig. 3 Life cycle GWP results for different carbon aerogel-based electrode scenarios. GOA-electrode represents the graphene oxide aerogel-based electrode. BA-electrode (Baseline), (Low), and (High) represent the nitrogen-doped biochar aerogel-based electrode produced from Entermorpha prolifera with medium (treated as baseline scenario), low, and high specific capacitances, respectively. The error bars indicate the absolute uncertainties of assessed results of productions of graphite, graphene oxide, and GOA were needed for the GOA production. The relatively higher input amount of chemicals and energy for GOA production could offset its GWP benefit originating from the higher electrochemical performance. It is also confirmed that the carbon aerogel-based electrode material production using EP is less mass/energy consumption-intensive than the graphite, possibly due to the inherently excellent fibrous structure of EP (Cui et al. 2016).

As illustrated in Fig. 3, the life cycle GWP was found to be greatly affected by the specific capacitance of EP-BA, and its value decreased by $32.1 \%$ when the specific capacitance changed from $190 \mathrm{~F} \mathrm{~g}^{-1}$ (low) to $280 \mathrm{~F} \mathrm{~g}^{-1}$ (high). This is because that less amount of EP-BA is needed with high specific capacitance than low specific capacitance for a supercapacitor unit production, thus resulting in less mass/energy input for EP-BA production. In the present study, we firstly reported the life cycle environmental performance of electrode material production using marine algae (e.g., the EP), and, therefore, the comparison of our results with reported results from other studies could not 
be discussed. However, we also noted that several studies have been conducted to investigate the life cycle environmental performance of marine algae used for other purposes, e.g., the bio-energy (Aitken et al. 2014; Brockmann et al. 2015; Ertem et al. 2017; Langlois et al. 2012) and biochar (used as soil amendment) (Bolognesi et al. 2019; Grierson et al. 2013). In the study of Sun et al. (2019), the life cycle GWPs of different algae-based bioenergy conversion systems, including bio-diesel production using methods of transesterification, hydrothermal liquefaction, and pyrolysis and bio-gas production using methods of anaerobic digestion with or without pretreatments of algae feedstock, ranged from - 173 to $265 \mathrm{~g} \mathrm{CO}_{2 \text {-eq }}$ (MJ bioenergy) ${ }^{-1}$. Moreover, the reported life cycle GWP in Grierson et al. (2013) reached up to $0.40-0.66 \mathrm{t} \mathrm{CO}_{2 \text {-eq }}(\mathrm{t}$ microalgae $)^{-1}$ for the biochar production and application systems, even though the soil carbon sequestration of biochar was taken into consideration. In sum, using the algae (e.g. the EP in this study) for electrode material production demonstrates a comparable life cycle GWP with other utilization technologies as mentioned above. However, the tradeoffs between the different algae use purposes are still needed to be discussed with more wide assessments related to environmental, economic, and policy aspects.

The GWP for GOA-electrode was estimated to be $1.96 \times 10^{-2} \mathrm{~kg} \mathrm{CO}_{2 \text {-eq }}$ (functional unit) ${ }^{-1}$ (Fig. 3). Previously, Cossutta et al. (2020) conducted a LCA for a supercapacitor production and application system using the reduced graphene oxide as electrode material, in which the estimated life cycle GWP was $211 \mathrm{~g} \mathrm{CO}_{2 \text {-eq }}$ for a supercapacitor with capacitance of $5 \mathrm{~F}$ under current technical level. This value could be further reduced to $36-89 \mathrm{~g} \mathrm{CO}_{2 \text {-eq }}$ under the future scenarios of "technological advancement" (elevation of graphene's specific capacitance) and "decarbonised" (renewable electricity sources) electricity mix (Cossutta et al. 2020). The reported results in Cossutta et al. (2020) were greatly higher than that assessed in the present study (19.6 g $\mathrm{CO}_{2 \text {-eq }}$ ), which could be possibly due to the differences in definition of life cycle system boundary and electrochemical performance of electrode materials. For example, comparing the system boundary definition in the present study, not only the electrode material production (reduced graphene oxide), but also the production, application and reuse of supercapacitor were included in the study of Cossutta et al. (2020). The reduced graphene oxide only accounted for less than $6.00 \%$ of the total amount of GWP for the supercapacitor production (Cossutta et al. 2020). Furthermore, the specific capacitance for the reduced graphene oxide used in Cossutta et al. (2020) was about $170 \mathrm{Fg}^{-1}$, while it was assumed to be $364 \mathrm{~F} \mathrm{~g}^{-1}$ for the GOA in the present study. This means the input amount of reduced graphene oxide in Cossutta et al. (2020) (1.35 g) was greatly higher than that in the present study $(0.014 \mathrm{~g})$.
As shown in Fig. 4a, the stages of EP-drying and EP-BA production were identified as the hotspots for life cycle GWP for the BA-electrode, which accounted for $31.4 \%$ and $65.8 \%$, respectively, of the total GWP. Previously, the large amount of energy consumption for algae feedstock drying has been regarded as a huge challenge when pyrolyzing the algae for bioenergy or carbon material (e.g., the biochar) production, because of its extremely high moisture content (95\%) and salinity (Ertem et al. 2017; Grierson et al. 2013; Sun et al. 2019). Sun et al. (2019) reported that the electricity consumption and corresponding $\mathrm{CO}_{2-\mathrm{eq}}$ emission accounted for $31.4 \%$ and $61.3 \%$ of the total net energy ratio and $\mathrm{CO}_{2 \text {-eq }}$ emission, respectively. Therefore, the innovative technologies for fresh algae feedstock dewatering and desalting with low energy input intensity or combined with renewable energy (e.g., the solar power) are needed to be designed (Grierson et al. 2013). Notably, there was also a potential carbon sequestration for the BA-electrode from the transformation of partial biogenic carbon in EP into BA-electrode. However, this positive mitigation in life cycle GWP could be negligible compared to the total amount of $\mathrm{CO}_{2-\mathrm{eq}}$ emission because of the extremely lower yield of EP-BA, e.g., $1 \mathrm{~kg}$ EP-BA produced from $672 \mathrm{~kg}$ fresh EP (Table 3). Therefore, more efforts should be made in the future studies to improve the yield of EP-BA. It is necessary to pay attention to that the EP feedstock is not anthropogenically planted to sequester carbon but is part of natural ecosystem. Based on this viewpoint, the carbon sequestration potential of biogenic carbon derived from EP should be deducted from the total life cycle GWP. The total life cycle GWP would change from $6.25 \times 10^{-3}-9.20 \times 10^{-3} \mathrm{~kg} \mathrm{CO}_{2 \text {-eq }}$ (functional unit) ${ }^{-1}$ to $6.30 \times 10^{-3}-9.27 \times 10^{-3} \mathrm{~kg} \mathrm{CO}_{2 \text {-eq }}$ (functional unit) ${ }^{-1}$, if the biogenic carbon sequestration derived from EP is not considered. This indicates a tiny effect of biogenic carbon sequestration on total life cycle GWP. Regarding the GOAelectrode, the graphene oxide production stage was found to contribute the largest proportion (84.1\%) of the total life cycle GWP for the GOA-electrode (Fig. 4b) due to the larger amount of chemicals (e.g., the resorcinol and methanal) consumed for the graphene oxide powder chemical oxidation (Table S3). This is similar to the EP-BA production, in which the chemicals (e.g., potassium hydroxide and sodium hypochlorite) input were also found as the main sources of life cycle GWP. Hence, optimizing the BA synthetic process and reducing chemicals input could effectively lower the overall life cycle GWP.

\subsection{Life cycle results of other impact categories}

The life cycle results of other impact categories are presented in Table 4. Compared to the GOA-electrode, the BAelectrodes showed significantly lower environmental impact values of SOD, OF-HH, OF-TE, M-EU, T-ET, F-ET, HNCT, 
Fig. 4 Hotspot life cycle stages identification for each environmental impact category: a BA-electrode scenario, b GOAelectrode scenario. GO and GOA represent the graphene oxide and $\mathrm{GO}$ aerogel. EP and EP-BA represent the Entermorpha prolifera and nitrogendoped biochar aerogel produced from EP

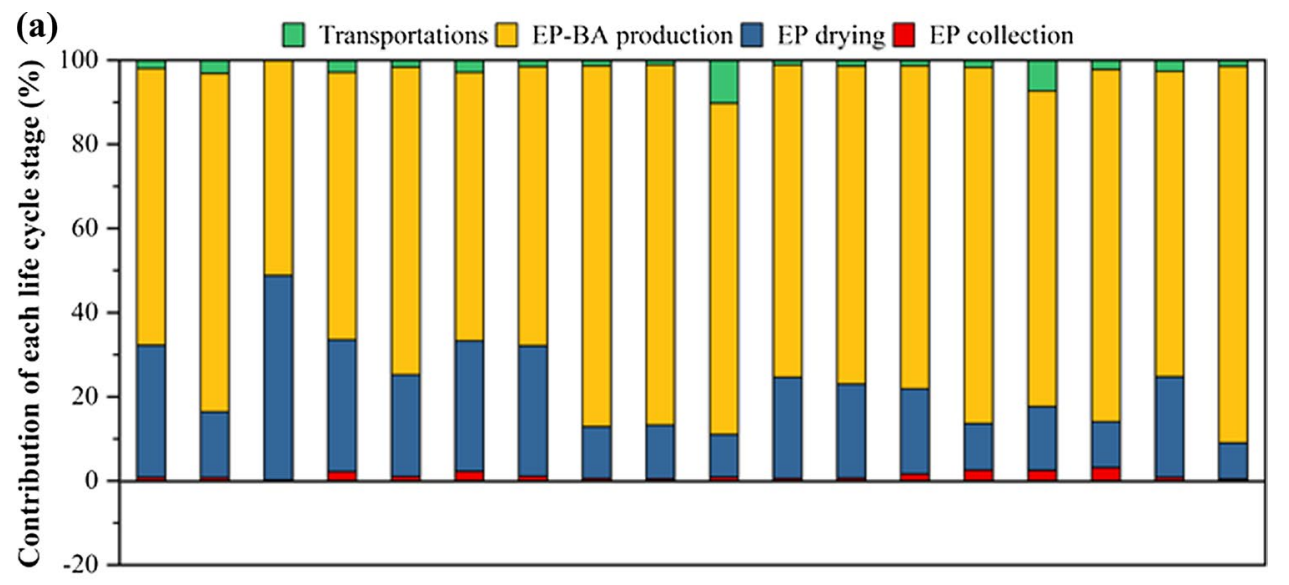

(b) $\square$ Transportations $\square$ GOA production $\square$ GO production $\square$ Graphite production

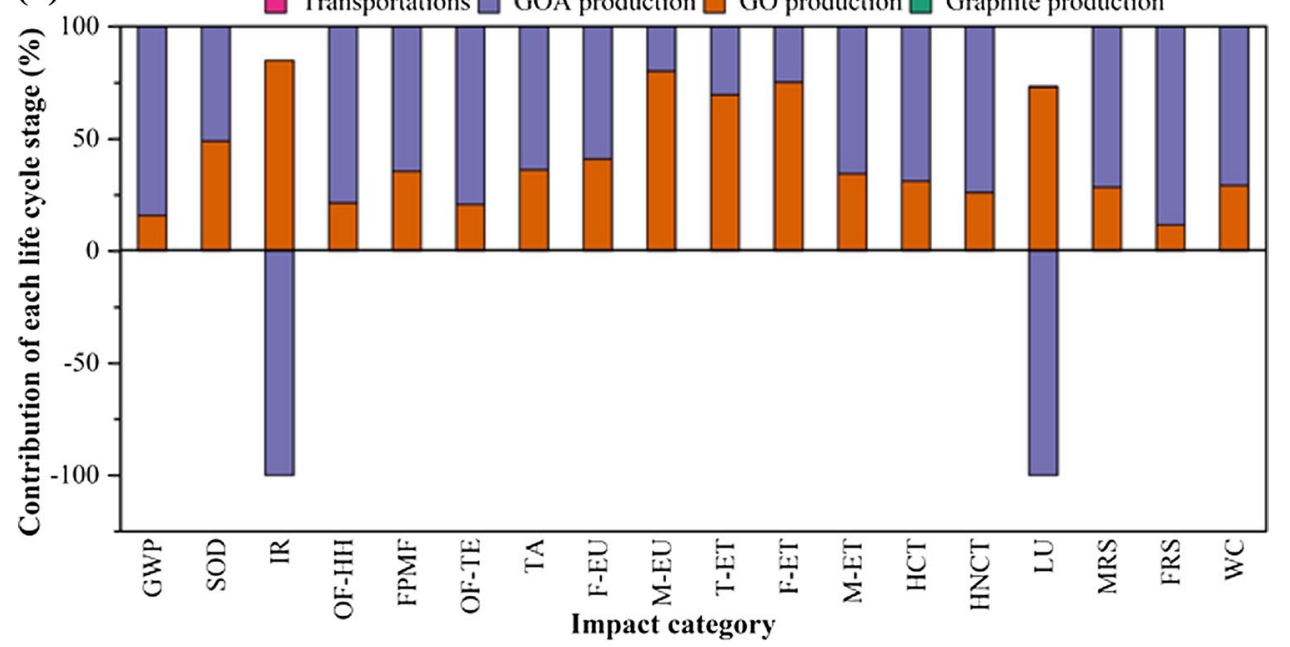

MRS, FRS, and WC, while significantly higher values of IR and LU. Notably, negative impact values of IR and LU were observed for the GOA-electrode, mainly contributed by the consumption of methanal during the GOA production stage, because the positive mitigations in IR and LU could be acquired during the methanal production process (Table S1). Furthermore, the specific capacitance indicated a great impact on the LCA results of BA-electrode, and the values of several impact categories, including FPMF, TA, $\mathrm{M}$-ET, and HCT, changed from the lower to the higher (or insignificant difference) compared to the GOA-electrode when the specific capacitance of EP-BA decreased from high $\left(280 \mathrm{~F} \mathrm{~g}^{-1}\right)$ to low $\left(190 \mathrm{~F} \mathrm{~g}^{-1}\right)$ levels (Table 4). According to the results presented above, we can conclude that the BAelectrode has smaller impacts on the environment than the GOA-electrode.

Consistent with the GWP, the resultant environmental impacts mainly originated from the productions of graphene oxide and GOA and stages of EP drying and EP-BA production for the BA-electrode and GOA-electrode, respectively (Fig. 4). Moreover, the transportation still exerted a tiny contribution to the overall results for the majority of impact categories as it for the GWP. This finding is consistent with the results published in other LCAs of algae energy systems (Sun et al. 2019), and it also supports our assumption in the "2.3 Life cycle inventory analysis" section. Unlike the GWP, the impact categories of M-EU, T-ET, and F-ET were more greatly affected by the graphene oxide production than the GOA production (Fig. 4b). This is because the environmental impacts of M-EU, T-ET, and F-ET for producing $1 \mathrm{~kg}$ graphene oxide or GOA were comparative (Tables S2 and S3), and the higher input of graphene oxide for per functional unit of GOA-electrode, therefore, resulted in the higher environmental impacts of these three categories than the GOA. Whereas, for other environmental impact categories (not including IR and LU), the environmental impact intensities for producing $1 \mathrm{~kg}$ GOA are extremely higher than that of producing $1 \mathrm{~kg}$ graphene oxide (Tables S2 and S3). This means that a smaller amount of GOA input could induce a higher environmental impact. 
Table 4 Results of environmental impacts for the GOA-electrode and BA-electrodes with different specific capacitances

\begin{tabular}{|c|c|c|c|c|}
\hline Impact category & BA-electrode (Baseline) ${ }^{\mathrm{a}}$ & BA-electrode (Low) & BA-electrode (High) & GOA-electrode \\
\hline $\mathrm{GWP} / \mathrm{kg} \mathrm{CO} \mathrm{CO}_{2 \text {-eq }}$ & $6.72 \mathrm{E}-03 \pm 3.77 \mathrm{E}-04$ & $9.20 \mathrm{E}-03 \pm 4.84 \mathrm{E}-04$ & $6.25 \mathrm{E}-03 \pm 3.50 \mathrm{E}-04$ & $1.96 \mathrm{E}-02 \pm 1.07 \mathrm{E}-03$ \\
\hline $\mathrm{SOD} / \mathrm{kg} \mathrm{CFC} 11_{\text {-eq }}$ & $2.97 \mathrm{E}-09 \pm 2.73 \mathrm{E}-10$ & $4.07 \mathrm{E}-09 \pm 4.72 \mathrm{E}-10$ & $2.77 \mathrm{E}-09 \pm 3.70 \mathrm{E}-10$ & $7.43 \mathrm{E}-09 \pm 1.98 \mathrm{E}-09$ \\
\hline $\mathrm{IR} / \mathrm{kBq} \mathrm{Co}-60_{-\mathrm{eq}}$ & $7.06 \mathrm{E}-04 \pm 3.73 \mathrm{E}-04$ & $9.67 \mathrm{E}-04 \pm 1.42 \mathrm{E}-03$ & $6.57 \mathrm{E}-04 \pm 9.88 \mathrm{E}-04$ & $-1.17 \mathrm{E}-05 \pm 1.44 \mathrm{E}-04$ \\
\hline $\mathrm{OF}-\mathrm{HH} / \mathrm{kg} \mathrm{NO} \mathrm{N}_{\mathrm{x} \text {-eq }}$ & $1.41 \mathrm{E}-05 \pm 8.05 \mathrm{E}-07$ & $1.93 \mathrm{E}-05 \pm 8.28 \mathrm{E}-07$ & $1.31 \mathrm{E}-05 \pm 5.81 \mathrm{E}-07$ & $2.85 \mathrm{E}-05 \pm 1.77 \mathrm{E}-06$ \\
\hline $\mathrm{FPMF} / \mathrm{kg} \mathrm{PM}_{2.5 \text {-eq }}$ & $1.28 \mathrm{E}-05 \pm 9.86 \mathrm{E}-07$ & $1.75 \mathrm{E}-05 \pm 1.72 \mathrm{E}-06$ & $1.19 \mathrm{E}-05 \pm 1.30 \mathrm{E}-06$ & $1.78 \mathrm{E}-05 \pm 1.96 \mathrm{E}-06$ \\
\hline OF-TE/kg NO & $1.43 \mathrm{E}-05 \pm 8.13 \mathrm{E}-07$ & $1.95 \mathrm{E}-05 \pm 8.34 \mathrm{E}-07$ & $1.33 \mathrm{E}-05 \pm 5.86 \mathrm{E}-07$ & $3.13 \mathrm{E}-05 \pm 1.83 \mathrm{E}-06$ \\
\hline $\mathrm{TA} / \mathrm{kg} \mathrm{SO}_{2-\mathrm{eq}}$ & $2.35 \mathrm{E}-05 \pm 2.08 \mathrm{E}-06$ & $3.22 \mathrm{E}-05 \pm 5.17 \mathrm{E}-06$ & $2.19 \mathrm{E}-05 \pm 3.39 \mathrm{E}-06$ & $2.96 \mathrm{E}-05 \pm 5.07 \mathrm{E}-06$ \\
\hline $\mathrm{F}-\mathrm{EU} / \mathrm{kg} \mathrm{P}_{\mathrm{eq}}$ & $2.62 \mathrm{E}-06 \pm 7.09 \mathrm{E}-07$ & $3.59 \mathrm{E}-06 \pm 1.28 \mathrm{E}-06$ & $2.44 \mathrm{E}-06 \pm 7.88 \mathrm{E}-07$ & $4.74 \mathrm{E}-06 \pm 1.98 \mathrm{E}-06$ \\
\hline $\mathrm{M}-\mathrm{EU} / \mathrm{kg} \mathrm{N} \mathrm{N}_{-\mathrm{eq}}$ & $2.00 \mathrm{E}-07 \pm 1.99 \mathrm{E}-08$ & $2.74 \mathrm{E}-07 \pm 3.11 \mathrm{E}-08$ & $1.86 \mathrm{E}-07 \pm 1.48 \mathrm{E}-08$ & $8.90 \mathrm{E}-07 \pm 7.62 \mathrm{E}-08$ \\
\hline T-ET/kg 1,4-DCB & $1.63 \mathrm{E}-02 \pm 5.09-03$ & $2.23 \mathrm{E}-02 \pm 5.23 \mathrm{E}-03$ & $1.52 \mathrm{E}-02 \pm 2.81 \mathrm{E}-03$ & $1.17 \mathrm{E}-01 \pm 2.63 \mathrm{E}-02$ \\
\hline F-ET/kg 1,4-DCB & $2.08 \mathrm{E}-04 \pm 3.91 \mathrm{E}-05$ & $2.85 \mathrm{E}-04 \pm 1.19 \mathrm{E}-04$ & $1.94 \mathrm{E}-04 \pm 4.96 \mathrm{E}-05$ & $9.92 \mathrm{E}-04 \pm 3.23 \mathrm{E}-04$ \\
\hline M-ET/kg 1,4-DCB & $2.87 \mathrm{E}-04 \pm 5.54 \mathrm{E}-05$ & $3.93 \mathrm{E}-04 \pm 1.68 \mathrm{E}-04$ & $2.67 \mathrm{E}-04 \pm 7.04 \mathrm{E}-05$ & $5.46 \mathrm{E}-04 \pm 3.93 \mathrm{E}-04$ \\
\hline $\mathrm{HCT} / \mathrm{kg} 1,4-\mathrm{DCB}$ & $2.31 \mathrm{E}-04 \pm 9.38 \mathrm{E}-05$ & $3.17 \mathrm{E}-04 \pm 4.01 \mathrm{E}-04$ & $2.15 \mathrm{E}-04 \pm 1.22 \mathrm{E}-04$ & $4.21 \mathrm{E}-04 \pm 3.22 \mathrm{E}-04$ \\
\hline HNCT/kg 1,4-DCB & $5.39 \mathrm{E}-03 \pm 1.60 \mathrm{E}-03$ & $7.38 \mathrm{E}-03 \pm 4.54 \mathrm{E}-03$ & $5.02 \mathrm{E}-03 \pm 1.95 \mathrm{E}-03$ & $1.55 \mathrm{E}-02 \pm 9.21 \mathrm{E}-03$ \\
\hline $\mathrm{LU} / \mathrm{m}^{2} \mathrm{a} \mathrm{crop}_{-\mathrm{eq}}$ & $1.40 \mathrm{E}-04 \pm 3.27 \mathrm{E}-05$ & $1.92 \mathrm{E}-04 \pm 4.36 \mathrm{E}-05$ & $1.30 \mathrm{E}-04 \pm 3.59 \mathrm{E}-05$ & $-5.64 \mathrm{E}-05 \pm 2.35 \mathrm{E}-04$ \\
\hline $\mathrm{MRS} / \mathrm{kg} \mathrm{Cu} \mathrm{eq}_{-\mathrm{eq}}$ & $1.57 \mathrm{E}-05 \pm 3.34 \mathrm{E}-06$ & $2.15 \mathrm{E}-05 \pm 5.26 \mathrm{E}-06$ & $1.46 \mathrm{E}-05 \pm 3.22 \mathrm{E}-06$ & $5.88 \mathrm{E}-05 \pm 1.78 \mathrm{E}-05$ \\
\hline FRS/kg oil & $1.74 \mathrm{E}-03 \pm 1.23 \mathrm{E}-04$ & $2.39 \mathrm{E}-03 \pm 1.95 \mathrm{E}-04$ & $1.62 \mathrm{E}-03 \pm 1.15 \mathrm{E}-04$ & $1.12 \mathrm{E}-02 \pm 5.31 \mathrm{E}-04$ \\
\hline $\mathrm{WC} / \mathrm{m}^{3}$ & $5.75 \mathrm{E}-05 \pm 1.62 \mathrm{E}-03$ & $7.87 \mathrm{E}-05 \pm 2.47 \mathrm{E}-03$ & $5.35 \mathrm{E}-05 \pm 1.25 \mathrm{E}-03$ & $2.99 \mathrm{E}-04 \pm 4.72 \mathrm{E}-03$ \\
\hline
\end{tabular}

${ }^{a}$ BA-electrode (Baseline) indicates the specific capacity for EP-BA is $261 \mathrm{~F} \mathrm{~g}^{-1}$, which represents the medium electrochemical performance of material and was used as the basic case. BA-electrode (Low) and BA-electrode (High) indicate the specific capacities for EP-BA are 190 and $280 \mathrm{~F} \mathrm{~g}^{-1}$, respectively, which represent the low or high electrochemical performances of material. GOA-electrode indicates the graphene oxide aerogel-based electrode

\subsection{Life cycle results of damage categories}

LCA results for the three damage categories, including human health, ecosystems, and resources, are illustrated in Fig. 5, and the environmental damages for the BA-electrodes are observed to be greatly lower than those of GOAelectrode. Specifically, the human health, ecosystems, and resources for BA-electrodes decreased by $35.8-56.4 \%$, 44.9-62.6\%, and 87.0-91.2\%, respectively, when compared to the GOA-electrode. Notably, the difference in ecosystems between the BA-electrodes and GOA-electrode may be insignificant due to the large uncertainties for this damage category (Fig. 5b). Expectedly, the damage value of resources calculated for the GOA-electrode demonstrated 7-11 times higher than those of BA-electrodes with different specific capacitances of EP-BA (Fig. 5c), possibly due to its input of more inorganic minerals and chemicals during the productions of graphene oxide and GOA. These results were consistent with those of environmental impacts stated in aforementioned sections. Therefore, combining the LCA results of environmental impacts and damages, it could be concluded that using the EP to produce carbon aerogel-based electrode material is much better than that of graphite due to its renewability and lower environmental implications.

The source structures of the overall environmental damages from each life cycle stage, as presented in Fig. 6, for the two electrode materials demonstrated similar results to the environmental impacts as discussed above. Regarding the BA-electrode, the environmental damages were mainly derived from the stages of EP-BA production (68.1-79.1\%) and EP drying (15.0-28.8\%) (Fig. 6a). For the GOA-electrode, the GOA production stage introduced the largest contribution to the overall environmental damage results (75.9-89.5\%), and followed by the graphene oxide production stage (10.4-24.0\%) (Fig. 6b).

\section{Highlights in the future studies}

In the present study, the selected EP feedstock is a type of wild algae with high uncertainties in spatial and temporal distributions, which could limit the continuous supply of this feedstock. In addition, there are big variations related to the mass/energy input and the resultant environmental impacts between the utilization systems of wild and cultivated algae. For example, Brockmann et al. (2015) found that the environmental impacts were 8.00-62.0\% lower for a bioethanol production system using the wild algae than that of the cultivated algae. In other relevant studies, the reported mass/ energy input and environmental impacts originating from the algae cultivation stage were also found to contribute a considerable proportion to the overall LCA results (Aitken et al. 2014; Brockmann et al. 2015; Langlois et al. 2012). Considering the industrial production of an electrode material, a 

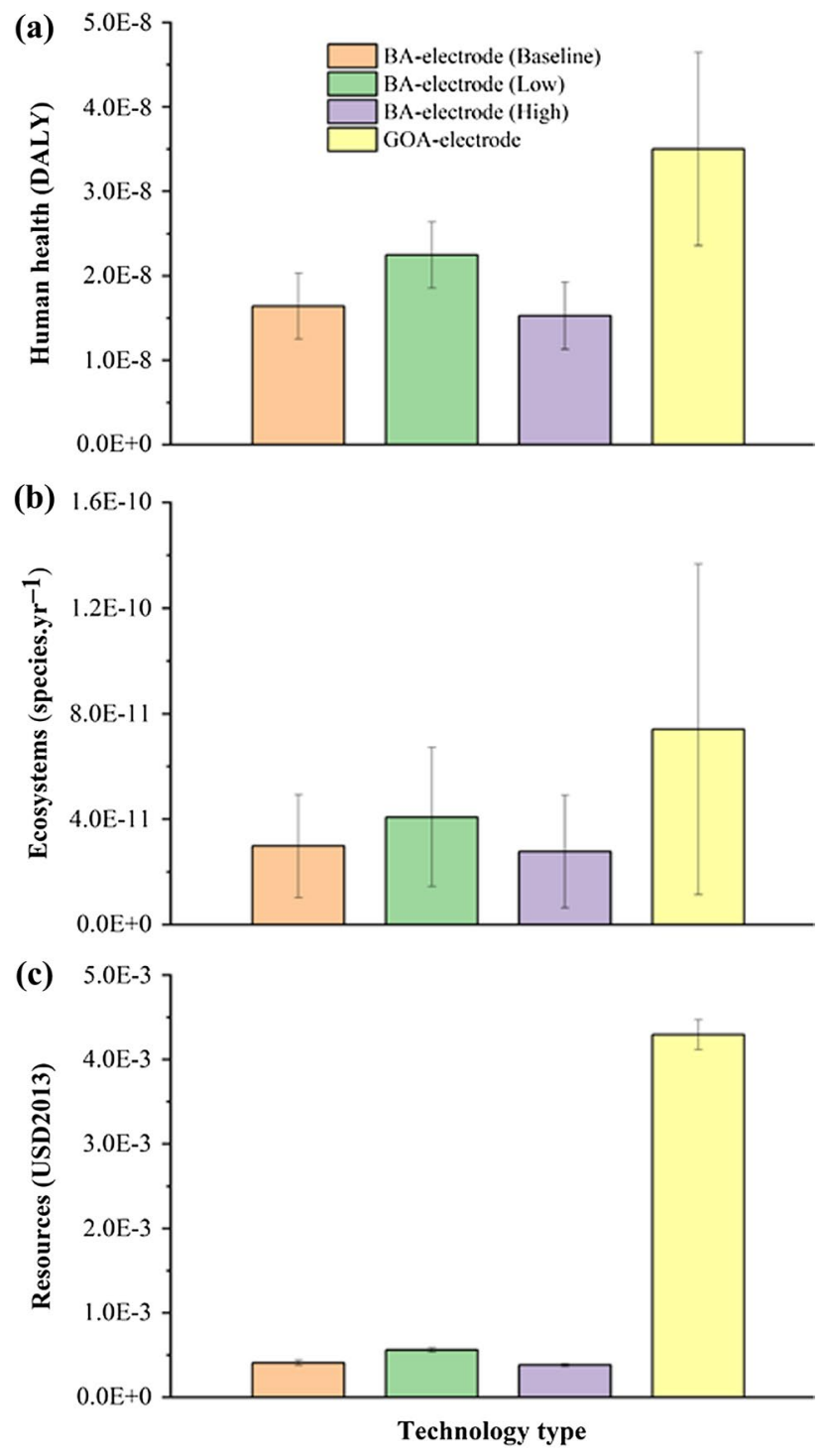

Fig. 5 Life cycle environmental damage results for different carbon aerogel-based electrode scenarios: a human health, b ecosystems, and c resources. GOA-electrode represents the graphene oxide aerogelbased electrode. BA-electrode (Baseline), (Low), and (High) represent the nitrogen-doped biochar aerogel-based electrode produced from Entermorpha prolifera with medium (treated as baseline scenario), low, and high specific capacitances, respectively. The error bars indicate the absolute uncertainties of assessed results

stable supply of raw feedstock is needed. Therefore, the cultivated algae should be more suitable than the wide collected algae as feedstock for BA material production. A detailed LCA related to this system from cultivated algae feedstock is also needed to be conducted.

In this study, an incomplete life cycle system boundary was defined for the BA-electrode system, because we just aimed to compare the supercapacitor electrode production using different carbon aerogel materials. Hence, the processes of supercapacitor production and utilization

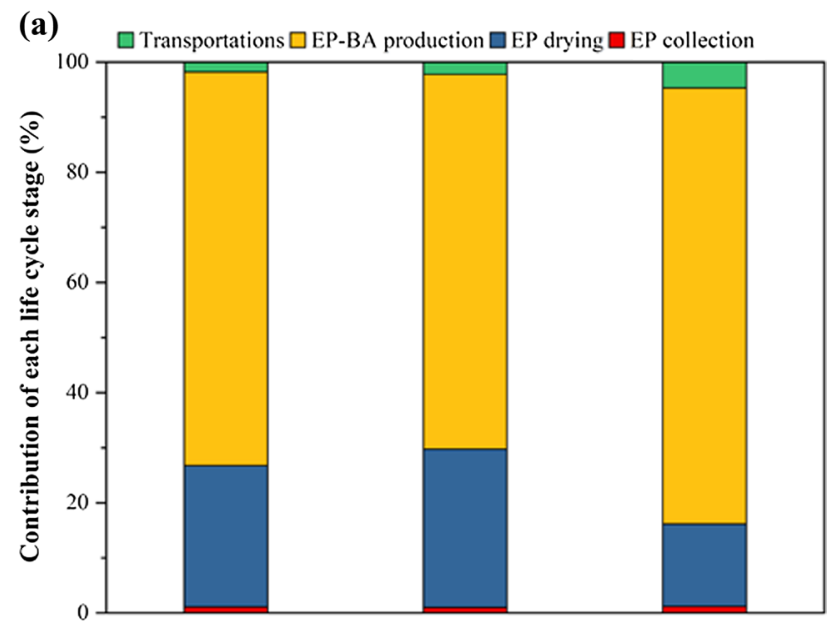

(b)
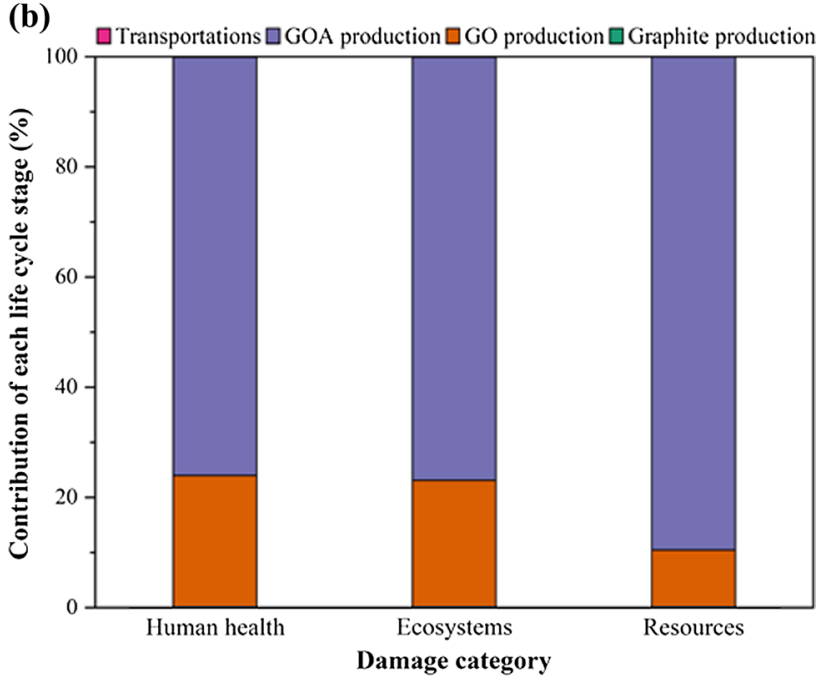

Fig. 6 Hotspot life cycle stages identification for each environmental damage category: a BA-electrode scenario, b GOA-electrode scenario. GO and GOA represent the graphene oxide and GO aerogel. EP and EP-BA represent the Entermorpha prolifera and nitrogendoped biochar aerogel produced from EP

were not included in the system boundary, because there was no difference in these processes between the supercapacitors using different electrode materials. However, this may hamper us to perform a better comparison among algae utilization technologies with different use purposes (e.g., the electrode, bioenergy, and biochar used as soil amendment), which is meaningful for producers or government involving economic activities and policy makings. In addition, the supercapacitors with carbon aerogel-based electrodes, such as the BA-electrode and GOA-electrode referred in this study, can be widely applied in manufacturing industry (Poonam et al. 2019; Zhang et al. 2018), including the applications in portable and miniaturized devices, photo-supercapacitors, and other backup power supplies for a small current power supply. What are the differences in environmental performance among varied 
supercapacitor application systems ought to be addressed in the future. Hence, extensive LCA studies with a comprehensive LCA boundary system ("cradle to grave") and a consistent assessment methodology system should be conducted. Furthermore, in the published algae bioenergy studies, the algae type has been suggested to potentially affect the yield of energy product, and subsequently influence on environmental performances due to the different carbohydrates compositions contained in different types of algae (Ertem et al. 2017; Greetham et al. 2018). This indicates that the algae type could potentially affect the yield and electrochemical performance of electrode material, and subsequently influence the environmental performances of algae-based electrode production and utilization system. Regarding this aspect, the experimental studies should be designed to screen the suitable algae types for the electrode production, which could help us to determine the optimal technical routes of BA-electrode production and utilization with best environmental performance.

\section{Conclusions}

According to the findings of our LCA, the BA-electrode scenario demonstrated smaller environmental implications on the environment than the GOA, meaning a positive mitigation potential in environmental implications would be acquired if using the renewable EP-BA to substitute the nonrenewable GOA. This is because fewer technical processes and amounts of chemical input from raw feedstock attraction to final product output were needed for the BA-electrode than GOA-electrode. However, energy consumption for the EP drying should be treated carefully owing to its large contribution to the overall LCA results. Furthermore, there are still some uncertainties for the BA-electrode scenario which should be addressed in the future studies, including raw feedstock acquisition (wild or cultivated), comparisons with other algae utilization technologies under a consistent assessment framework, and more comprehensive assessment comprising economic and policy aspects. Overall, this work provides valuable information to guide the supercapacitor electrode production using BA-electrode produced from algae feedstock from the environmental perspective.

Supplementary Information The online version contains supplementary material available at https://doi.org/10.1007/s42773-021-00122-1.

Acknowledgements We appreciate the financially support from the National Natural Science Foundation of China (51808303, 51672143, 21976185 and 21501105), Science and Technology Support Plan for Youth Innovation of Colleges in Shandong Province (DC2000000961), Taishan Scholar Program, Outstanding Youth of Natural Science in Shandong Province (JQ201713).
Author contributions ZJ original paper writing, methodology, experiments; YZ experiments, writing; YL data analysis, editing; FK data analysis, review and editing; DY supervision.

\section{Declarations}

Conflict of interest The authors declare that they have no conflict of interest.

Consent for publication The corresponding author consents on behalf of all the authors that this is original work and has permission to be published.

Open Access This article is licensed under a Creative Commons Attribution 4.0 International License, which permits use, sharing, adaptation, distribution and reproduction in any medium or format, as long as you give appropriate credit to the original author(s) and the source, provide a link to the Creative Commons licence, and indicate if changes were made. The images or other third party material in this article are included in the article's Creative Commons licence, unless indicated otherwise in a credit line to the material. If material is not included in the article's Creative Commons licence and your intended use is not permitted by statutory regulation or exceeds the permitted use, you will need to obtain permission directly from the copyright holder. To view a copy of this licence, visit http://creativecommons.org/licenses/by/4.0/.

\section{References}

Aitken D, Bulboa C, Godoy-Faunde A, Turrion-Gomez JL, AntizarLadislao B (2014) Life cycle assessment of macroalgae cultivation and processing for biofuel production. J Clean Prod 75:45-56. https://doi.org/10.1016/j.jclepro.2014.03.080

Bolognesi S, Bernardi G, Callegari A, Dondi D, Capodaglio AG (2019) Biochar production from sewage sludge and microalgae mixtures: properties, sustainability and possible role in circular economy. Biomass Conv Bioref. https://doi.org/10.1007/ s13399-019-00572-5

Brockmann D, Pradinaud C, Champenois J, Benoit M, Hélias A (2015) Environmental assessment of bioethanol from onshore grown green seaweed. Biofuel Bioprod Bior 9:696-708. https://doi.org/ 10.1002/bbb. 1577

Cossutta M, Vretenar V, Centeno TA, Kotrusz P, McKechnie J, Pickering SJ (2020) A comparative life cycle assessment of graphene and activated carbon in a supercapacitor application. J Clean Prod 242:118468. https://doi.org/10.1016/j.jclepro.2019.118468

Cui J, Xi Y, Chen S, Li D, She X, Sun J, Han W, Yang D, Guo S (2016) Entermorpha prolifera-green-tide as sustainable source for carbonaceous aerogels with hierarchical pore to achieve multiple energy storage. Adv Funct Mater 26:8487. https://doi.org/10.1002/adfm. 201603933

Dasan YK, Lam MK, Yusup S, Lim JW, Lee KT (2019) Life cycle evaluation of microalgae biofuels production: effect of cultivation system on energy, carbon emission and cost balance analysis. Sci Total Environ 688:112-128. https://doi.org/10.1016/j.scitotenv. 2019.06.181

Ertem FC, Neubauer P, Junne S (2017) Environmental life cycle assessment of biogas production from marine macroalgal feedstock for the substitution of energy crops. J Clean Prod 140:977-985. https://doi.org/10.1016/j.jclepro.2016.08.041

Gao X, Xing W, Zhou J, Wang G, Zhuo S, Liu Z, Xue Q, Yan Z (2014) Superior capacitive performance of active carbons derived from 
Entermorpha prolifera. Electrochim Acta 133:459-462. https:// doi.org/10.1016/j.electacta.2014.04.101

Garcia-Bordeje E, Victor-Roman S, Sanahuja-Parejo O (2018) Control of the microstructure and surface chemistry of graphene aerogels via $\mathrm{pH}$ and time manipulation by a hydrothermal method. Nanoscale 10:3526-3539. https://doi.org/10.1039/C7NR08732B

Glogic E, Adán-Más A, Sonnemann G, Montemor MF, GuerlouDemourgues L, Young SB (2019) Life cycle assessment of emerging $\mathrm{Ni}-\mathrm{Co}$ hydroxide charge storage electrodes: impact of graphene oxide and synthesis route. RSC Adv 9:18853-18862. https://doi.org/10.1039/c9ra02720c

Greetham D, Zaky A, Makanjuola O, Du C (2018) A brief review on bioethanol production using marine biomass, marine microorganism and seawater. Curr Opin Green Sust Chem 14:53-59. https:// doi.org/10.1016/j.cogsc.2018.06.008

Grierson S, Strezov V, Bengtsson J (2013) Life cycle assessment of a microalgae biomass cultivation, bio-oil extraction and pyrolysis processing regime. Algal Res 2:299-311. https://doi.org/10. 1016/j.algal.2013.04.004

Guinée JB, Heijungs R, Huppes G, Zamagni A, Masoni P, Buonamici R, Ekvall T, Rydberg T (2011) Life cycle assessment: past, present, and future. Environ Sci Technol 45:90-96. https://doi.org/ 10.1021/es $101316 \mathrm{v}$

Guo R, Lv C, Xu W, Sun J, Zhu Y, Yang X, Li J, Sun J, Zhang L, Yang D (2020a) Effect of intrinsic defects of carbon materials on the sodium storage performance. Adv Energy Mater. https://doi.org/ 10.1002/aenm.201903652

Guo Z, Xin Q, Zang Y, Lin J (2020b) Effects of graphene oxide doping content and $\mathrm{pH}$ on energy storage performance of graphene aerogel. Chin J Eng. https://doi.org/10.13374/j.issn2095-9389.2020. 01.07.001 ((In Chinese with English abstract))

Hellweg S, i Canals LM (2014) Emerging approaches, challenges and opportunities in life cycle assessment. Science 344:1109. https:// doi.org/10.1126/science. 1248361

ISO (2006) ISO 14044: Environmental managementdlife cycle assessmentdrequirements and guidelines. International Organization for Standardization.

ISO-14040 (2006) Environmental management-life cycle assessment: principles and framework. Int Organ Standard

ISO-14044 (2006) Environmental management-life cycle assessment: requirements and guidelines. Int Organ Standard

Jiang Z, Zheng H, Xing B (2021) Environmental life cycle assessment of wheat production using chemical fertilizer, manure compost, and biochar-amended manure compost strategies. Sci Total Environ 760:143342. https://doi.org/10.1016/j.scitotenv.2020.143342

Langlois J, Sassi JF, Jard G, Steyer JP, Delgenes JP, Hélias A (2012) Life cycle assessment of biomethane from offshore-cultivated seaweed. Biofuel Bioprod Biorefin 6:387-404. https://doi.org/ 10.1002/bbb. 1330

Li D, Wang Y, Sun Y, Lu Y, Chen S, Wang B, Zhang H, Xia Y, Yang D (2018) Turning gelidium amansii residue into nitrogen-doped carbon nanofiber aerogel for enhanced multiple energy storage. Carbon 137:31-40. https://doi.org/10.1016/j.carbon.2018.05.011

Lu L, Yu W, Wang Y, Zhang K, Zhu X, Zhang Y, Wu Y, Ullah H, Xiao X, Chen B (2020) Application of biochar based materials in environmental remediation: from multi level structures to specific devices. Biochar 2:1-31. https://doi.org/10.1007/ s42773-020-00041-7

Lv C, Xu W, Liu H, Zhang L, Chen S, Yang X, Xu X, Yang D (2019) $3 \mathrm{D}$ sulfur and nitrogen codoped carbon nanofiber aerogels with optimized electronic structure and enlarged interlayer spacing boost potassium-ion storage. Small 15:1900816. https://doi.org/ 10.1002/smll.201900816

Malara A, Pantò F, Santangelo S, Antonucci PL, Fiore M, Longoni G, Ruffo R, Frontera P (2020) Comparative life cycle assessment of $\mathrm{Fe}_{2} \mathrm{O}_{3}$-based fibers as anode materials for sodium-ion batteries.
Environ Dev Sustain 23:6786-6799. https://doi.org/10.1007/ s10668-020-00891-y

Miller JR, Simon P (2008) Electrochemical capacitors for energy management. Science 321:651-652. https://doi.org/10.1126/science. 1158736

Muñoz E, Curaqueo G, Cea M, Vera L, Navia R (2017) Environmental hotspots in the life cycle of a biochar-soil system. J Clean Prod 158:1-7. https://doi.org/10.1016/j.jclepro.2017.04.163

$\mathrm{Ng} \mathrm{CH}$, Lim HN, Lim YS, Chee WK, Huang NM (2015) Fabrication of flexible polypyrrole/graphene oxide/manganese oxide supercapacitor. Int J Energy Res 39:344-355. https://doi.org/10.1002/er.3247

Padashbarmchi Z, Hamidian AH, Khorasani N, Kazemzad M, McCabe A, Halog A (2015) Environmental life cycle assessments of emerging anode materials for Li-ion batteries-metal oxide NPs. Environ Prog Sustain Energy 34:1740-1747. https://doi.org/10. 1002/ep. 12148

Pandolfo AG, Hollenkamp AF (2006) Carbon properties and their role in supercapacitors. J Power Sources 157:11-27. https://doi.org/10. 1016/j.jpowsour.2006.02.065

Poonam SK, Arora A, Tripathi SK (2019) Review of supercapacitors: materials and devices. J Energy Storage 21:801-825. https://doi. org/10.1016/j.est.2019.01.010

Raymundo-Piñero E, Leroux F, Béguin F (2006) A high-performance carbon for supercapacitors obtained by carbonization of a seaweed biopolymer. Adv Mater 18:1877-1882. https://doi.org/10.1002/ adma.200501905

Roberts KG, Gloy BA, Joseph S, Scott NR, Lehmann J (2010) Life cycle assessment of biochar systems: estimating the energetic, economic, and climate change potential. Environ Sci Technol 44:827-833. https://doi.org/10.1021/es902266r

Sun Y, Wu Q, Shi G (2011) Graphene based new energy materials. Energy Environ Sci 4:1113-1132. https://doi.org/10.1039/c0ee0 0683a

Sun CH, Fu Q, Liao Q, Xia A, Huang Y, Zhu X, Reungsang A, Chang HX (2019) Life-cycle assessment of biofuel production from microalgae via various bioenergy conversion systems. Energy 171:1033-1045. https://doi.org/10.1016/j.energy.2019.01.074

Wang C, Liu Q, Yuan W (2009) Optimization of Enteromorpha Prolifra drying process. J Qingdao u 24:94-98 ((In Chinese with English abstract))

Wang C, Li F, Qu H, Wang Y, Yi X, Qiu Y, Zou Z, Luo Y, Yu B (2015) Fabrication of three dimensional carbon nanotube foam by direct conversion carbon dioxide and its application in supercapacitor. Electrochim Acta 158:35-41. https://doi.org/10.1016/j.electacta. 2015.01.112

Wang J, Nie P, Ding B, Dong S, Hao X, Dou H, Zhang X (2017) Biomass derived carbon for energy storage devices. J Mater Chem A 5:2411-2428. https://doi.org/10.1039/c6ta08742f

Wu H, Gong Y, Yu Y, Huang K, Wang L (2019) Superior "green" electrode materials for secondary batteries: through the footprint family indicators to analyze their environmental friendliness. Environ Sci Pollut R 26:36538-36557. https://doi.org/10.1007/ s11356-019-06865-6

Xu W, Lv C, Zou Y, Ren J, She X, Zhu Y, Zhang Y, Chen S, Yang X, Zhan T, Sun J, Yang D (2019) Mechanistic insight into highefficiency sodium storage based on N/O/P-functionalized ultrathin carbon nanosheet. J Power Sources 442:227184. https://doi.org/ 10.1016/j.jpowsour.2019.227184

Zhang L, Zhao X (2009) Carbon-based materials as supercapacitor electrodes. Chem Soc Rev 38:2520-2531. https://doi.org/10.1039/ b813846j

Zhang L, Hu X, Wang Z, Sun F, Dorrell DG (2018) A review of supercapacitor modeling, estimation, and applications: a control/management perspective. Renew Sust Energy Rev 81:1868-1878. https://doi.org/10.1016/j.rser.2017.05.283 
Zou Y, Gu Y, Hui B, Yang X, Liu H, Chen S, Cai R, Sun J, Zhang $X$, Yang D (2020) Nitrogen and sulfur vacancies in carbon shell to tune charge distribution of Co6Ni3S 8 core and boost sodium storage. Adv Energy Mater 10:1904147. https://doi.org/10.1002/ aenm.201904147 